\title{
"A question of bank notes, cars, and houses!" Matchmaking and the Moral Economy of Love in Urban China
}

\author{
JEAN-BAPTISTE PETTIER \\ Institute of Social and Cultural Anthropology, and Affective Societies \\ Collaborative Research Center, Freie Universität Berlin, Germany
}

"I don't know what love is." It was through such words that my interest in the topic of love (aiqing) in China was originally awakened. From the beginning of my fieldwork in Beijing in 2006 through my departure from Chengdu in 2010, the two cities where I carried out research, this particular phrase resurfaced time and time again in my conversations with young people about their experiences of current or previous relationships. It recurred enough times to establish that the sentence was more than rhetorical and also more than a simple byproduct of my interviewees' encounter with an anthropologist coming from France, a country they were used to labeling as "romantic." With this phrase, they conveyed to me that they were unsure how and when they could identify love within their own lives. I also understood it as a sign of the ambiguous cultural and social role that the notion of love has come to play in Chinese public discourse.

What accounts for the ambiguous place that romantic love now occupies in Chinese society? I argue that a new complex of romantic love has emerged, which is an original and recent synthesis between the tradition of parental arrangement and the long-controversial question of the place of love in modern China. Combining historically opposed positions, this complex emphasizes the importance of romantic love while maintaining decisive exclusionary

Acknowledgments: A preliminary version of this article was presented in a conference organized by Sun Wanning and Yang Ling at the University of Xiamen in November 2017, where it benefitted from the discussion of Geng Song (Hong Kong University). Then, at the "Culture, Power, Social Change" seminar of the Department of Anthropology at UCLA in October 2018, it profited from an insightful reading by Akhil Gupta and comments and encouragements from Yunxiang Yan. Eric Sinski at UCLA worked diligently to clarify the English. Lastly, the attentive readings of the anonymous $\mathrm{CSSH}$ reviewers were crucial to producing the final version. 
mechanisms in the hands of parents. In nineteenth-century East-Asia, debates surrounding love arose following bellicose encounters with the Western colonial empires, which used military force to coerce East Asian countries into signing trade agreements and to open trading posts along their coasts. Their military victories generated a questioning of the reasons behind East Asia's comparative technological backwardness. In Europe, the philosophical debates of the time attributed the progress achieved since the Enlightenment in part to a new culture allowing more autonomy for the younger generations (see Luhmann 2010). Central here was the freedom to choose one's own marriage partner based on personal sentiments. Though the notion of sentiments, qing, was strong in Chinese literary traditions (Bisetto 2012; Huang 1998), it did not seem to capture the exact contours of love in the discourses of the modernist Westerners, who were describing China as lacking even sympathy (e.g., Smith 1894: 199). This alleged absence of love was considered to be one of the major reasons for Eastern countries' difficulties in modernizing. ${ }^{1}$ Intense political debates and modernization movements ensued that centered on marriage, the place of women in society, and romantic love. Between the 1870s and the 1930s, these debates traversed all of East Asia, from Japan (Butel 2011; Edwards 1989; Morton 1997; Ryang 2006; Suzuki 2010), to Korea (Kendall 1996; Kim 1974; Kim 2013; Kwon 2005), China (Lee 1973; Lee 2007; Liu 2003; Liu 1995), and Vietnam (Marr 1981; Nguyễn 1995; Phinney 2008).

In China, these heated debates led the Communist Party to forbid the intervention of "third parties" in marriage decisions as soon as it came to power. But the active promotion of individual choice did not put an end to matchmaking (Croll 1981: 31; Liu 2000: 71-75; Pettier 2017; 2019; Yan 2003: 62-63). Indeed, the state itself often played an active go-between role during Maoist times through the work units' (danwei) control over most aspects of life (Diamant 2000: 205). Romantic love was associated with bourgeois attitudes and condemned as such. Its place within society remained a fundamental ideological and political battleground until after the Maoist era (Zhang 2005). Since the 1980s, the development of new marriage bureaus has been hailed as necessary, and the state has attempted to supervise their development rather than forbid them (Domenach and Hua 1987: 32-37; Pettier 2019: 8 n13). In 2000s China, the continuation of controversies over love marriage and individual choice was particularly visible in debates surrounding the practices of acquaintanceship known as xiangqin. Often inadequately translated into English as "blind date," this notion implies the search for a mate following criteria collectively agreed upon within the family of the prospective bachelor or bachelorette. The search is

\footnotetext{
${ }^{1}$ Love's place in societies' progress, and its linkage with cultural and racial theorizations, were well-covered in nineteenth-century philosophical and scientific literatures, but I cannot address those here. Note, though, the work of Henry Finck (1899), who systematically applied an evolutionist approach to the notion of love.
} 
collective, and the matchmaker can be either a relative or a professional. In the context of rapidly increasing social inequality and diversification of lifestyles, these practices engage moral debates about romantic love and the importance it should be given, which can no longer be understood as a national attempt to catch up with Western modernity. Instead, I will argue, the continuing debate surrounding the place of love reveals the shaping of new morals of social differentiation and illuminates some current moral tensions and new intergenerational arrangements within Chinese society. In turn, these new arrangements raise questions about our understandings of the role romantic sentiments play in society more broadly.

In earlier scholarship, love has been analyzed on vastly different scales, from being a transformative moral experience to be examined at the level of individuals' specific stories (e.g., Wynn 2015; Zigon 2014), to a civilizational and political issue transforming societies at the scale of continents (e.g., de Rougemont 1983; Reddy 2012). Romantic love has been considered a discourse that appears solely in the context of modernization, de facto protecting the emergence of individuals' democratic rights (Luhmann 2010). Others have seen it as tied to the development and transformations of capitalism (MacFarlane 1987) and as playing a role in modernity and globalization (Hirsch and Wardlow 2006; Padilla et al. 2007), but also as an ideal emerging in certain restrictive and highly competitive societies where it offers an escape from everyday reality (Lindholm 1998). Conversely, the question of the universality of romantic love has been a controversial issue (Goody 2006).

These different arguments began to be tested through comparative analyses of conceptual understandings of love across cultures and histories (Beall and Sternberg 1995; de Munck, Korotayev, and Khaltourina 2009; de Munck et al. 2011; Jankowiak 1995; Jankowiak et al. 2015; Nelson and Yon 2018). That said, one generally acknowledged dimension of romantic love is that it is linked to the reproduction of social groups (Kalmijn 1998). Eva Illouz, in particular, has underscored how "romance is a good unequally distributed" in the social structure, following class lines and material means (1997: 294). Pierre Bourdieu, who carried out research on the unchosen celibacy of firstborn peasant sons, the farm inheritors, in the context of the economic upheaval of southwest rural France in the 1950s (2008), described love as acting as a tool of social reproduction. According to him, it makes the work a "spontaneous decoding of one habitus by another ... discouraging socially discordant relationships, encouraging well-matched relationships, without these operations ever having to be formulated other than in the socially innocent language of likes and dislikes" (1984: 243).

This article examines these previous lines of thought in the context of contemporary Chinese society and asserts that an original formation of love has arisen there over the last two decades, which partially reconciles opposing views that made the place of love conflictual in earlier phases of the 
modernization process. Among the urban middle-class populations that I have been working with, this arrangement consists in a strong rhetorical emphasis on the importance of romantic love, in conjunction with a balanced distribution of the power to make marriage decisions between the parental and bachelors' generations. As I will explain, the latter is intended as a fallback mechanism to protect families against the "blindness" attributed to love. The social reproductive mechanisms encoded within the arrangement of love emphasized by Bourdieu are here outsourced to the older generation, while romantic love is still held in high esteem but confined within one's own socioeconomic milieu. This new moral economy, which produces and distributes moral values surrounding love in a way that favors the upper-middle-class, ${ }^{2}$ rests on a certain intergenerational arrangement.

It is also promoted in multiple ways by the state. One way is by emphasizing the importance of individual sentiments and family affection by making the interdependence between the younger and older generations both mandatory and necessary through its legal and economic policies (Piquet and Laliberté 2020). Another is by actively censoring materialist discourses in the public space, both ostentatious demonstrations of wealth and expression of envy of it. These two strategies differ starkly from those of the state during the Maoist era, which condemned romantic love as bourgeois, opposed the traditional discretionary power of the parental generation, and privileged comrade political solidarity over intra-familial and particularistic affective ties. By contrast, the new moral economy produces socially qualifying and disqualifying moral labels through the emphasis it puts on the notion of love. While the new middle- and upper-middle-classes-whom I identify through their managing and upscale professions and their administrative residential statuses within capital citiesare described as sensible and loving, "outsiders" and migrants from lower-rank cities and the countryside are abstractly produced as a materialist and needy category of people, disqualified from love.

To explain this process, I will examine how it is concretely shaped in the parental acquaintanceship markets, and contrast participants' perspectives, including their criticism that love should be more important in mate choices, with perspectives of two young rural migrants in Chengdu. The paper begins by introducing present-day xiangqin, marriage through presentation, particularly in the context of urban marriage corners where parents search for potential mates for their children. The second part examines criticisms of this phenomenon over its allegedly materialistic orientation. I explain how the participants justify the practice as a guarantee against "outsiders," who are viewed as trying to elevate themselves socially and economically through advantageous marriages. Two

2 Here I follow Didier Fassin's (2009) approach to the notion of moral economy, but retain Palomera and Vetta's emphasis on social class (2016). 
subsequent parts will put these arguments in perspective with the stories of two so-called "outsiders," a woman and a man who are both young rural migrants. I show their awareness and experience of the stigma they confront and their disqualification as lovers.

Based on these cases, the paper's concluding parts show how this moral economy of love organizes the reproduction of society through sincere moral sentiments, to the advantage of the middle- and upper-middle-classes. By examining the ways in which these diverse parties deal with their feelings and material difficulties, I analyze the moral questions my interlocutors ask about love, along with the larger social implications of the choices they make. I will suggest that the ambiguity that characterizes the discourse on romantic love and matchmaking practices cannot be separated from ongoing class stratification processes within Chinese society. I delineate the renewing of today's urban elites' normative morality, in which love politics play a central role. This also reflects intergenerational co-dependency within the urban middle classes, and the related moral economy of love in present-day urban China. The complex of romantic love and how it splits two widely acknowledged dimensions of lovesocial reproduction through individual sentimental idealization-between the generations of parents and lovers also elucidates a contradiction within Chinese society today: the coexistence of a continuing importance of the family alongside rising individualism.

\section{THE XIANGQIN PHENOMENON}

In Chinese language, the word xiangqin describes the search for a potential marriage partner on behalf of another person and introducing the potential couple. Xiangqin practices are common and often visible in the public space. Throughout the past two decades the term has denoted several phenomena: meetings of parents of single children (Pettier 2016; 2020; Sun 2012; Zhang and Sun 2014), often labeled as "marriage corners," which happen in public parks; marriage agencies and the services of professional matchmakers (Pettier 2019); massive events where thousands of young singles meet; and TV dating shows (see Chen 2016; Kong 2013; Li 2015; Wei and Zhen 2014) and TV series and films on the theme of matchmaking. ${ }^{3}$ All these activities and related media productions have developed in parallel with online dating through websites and messaging platforms; they have not been diminished by the development of selfdirected mate searches by the younger generations. Between parents' meetings and television broadcasts, marriage agencies, and informal family arrangements, the xiangqin phenomenon directly involves most of the Chinese population. To various degrees, virtually everyone who is single and over twenty is involved in,

\footnotetext{
${ }^{3}$ As this article will make clear, Chinese society today is heteronormative, so these practices focus on heterosexual couples.
} 
or at least must deal with, matchmaking searches organized for them, at times against their will. ${ }^{4}$ Even when their parents do not engage directly in the search, bachelors and bachelorettes as well as their parents are usually pressed by neighbors and relatives, who ask if a marriage is planned and spontaneously offer to introduce appropriate candidates. These pressures are too constant and normalized to ignore, and young people often resent them and express frustration and anxiety over the issue of their marriage. Older and married people, for their part, participate by introducing potential partners to the non-married persons around them.

In order to understand the moral controversies around xiangqin, I repeatedly took part in parental gatherings at six different parks in Beijing and Chengdu (three in each). I discussed the phenomenon with participants and, when possible, conducted lengthy interviews with them and/or their children. I also paid many visits to professional matchmaking agencies in Chengdu and took part in bachelor gatherings in that city. None of these settings were part of my initial research design, which focused on questions of youth intimacy. I started to visit them because my fieldwork with young people alerted me to how heavily the question of marriage was falling on their shoulders. This prompted me to switch to studying the parental side of the scene for the last year of my longitudinal research.

The young people I worked with, most in their early to mid-twenties, typically highlighted the pressure they felt from their families, relatives, and extended networks to quickly find a partner and marry. In this context, the question of love kept resurfacing in various discourses as a matter which, while considered opaque, was universally declared to be insufficiently regarded in China. Offered as proof were the matchmaking practices, in which these students and young workers were often directly or indirectly involved. This discourse was also palpable in public discussions of xiangqin practices, ranging from TVshows to parental meetings. It is important to note that in all these cases the topic of love was always raised by my interlocutors themselves. Over and again they put forward love, but in a negative way, as a sentiment that was not given enough importance.

Of all the various types of gatherings that I attended, the parental meetings stood out to me. There one can observe hundreds of mostly local ${ }^{5}$ parents circulating in specific corners of city parks with little boards displaying detailed information about their child, as well as requirements for their prospective partner.

\footnotetext{
4 This dimension is not unique to China, and Jordanian society offers a comparable case (see Adely 2016: 107-8).

5 In Chengdu, a few parents I met had attended these marriage corners in other places, either because they split their life between two cities or out of curiosity. One father told me how impressed he had been by the number of participants in a similar meeting in the city of Xi'an. In Beijing, a few outsiders occasionally attended the meetings out of curiosity, having heard about them in massmedia. They visited the place while traveling through the city. Most participants, though, are local residents.
} 
The most common requirements pertain to age, height, level of education, place of origin, type of employment, and income. In the context of these central locations, the participants' criteria reflect that they are at least modestly comfortable: they have studied and held managerial positions, and most own an apartment in these highly coveted areas. In addition, the child on behalf of whom they seek a partner usually is highly educated and has already started a promising career. These families are beneficiaries of the reform era, even if their situations are not without challenges. The wildfire development of "marriage corners," in which hundreds of these better-off parents search for spouses for their children, are a product of the difficulties of intergenerational transmission they face and the competitiveness of contemporary urban China. This situation can be hurtful and disturbing, as indicated by the highly emotional engagement of some participants (see Pettier 2016). Yet, even the participating parents know these marriage corners bring little success in finding matches. I have previously argued that the effect and purpose of these matchmaking activities lie in their prescriptive and normative dimensions (Pettier 2020). I maintain that romantic love plays a pivotal role here.

To understand why this scene has developed as it has, it is important to remember that China's government implemented a national policy of birth control about three decades ago, and that this policy was most strictly implemented in the cities, where few exceptions occurred or were granted. In the present urban population, the large majority of families have only had one child, and the first generation of these city children have now reached marriageable age. The birth control policy was imposed at the same time as the policies to open up the economy, which initiated China's rapid development starting in the 1980s (Fong 2004; Greenhalgh and Winkler 2005). Consequently, this new generation, the first born under this particular set of historical conditions, is very much under societal scrutiny. Their problems and difficulties are thoroughly discussed in the national press. Their late marriages and higher levels of divorce are important topics of everyday conversations, since it is supposed that the priority given to only-children's educations might have produced a whole generation of selfish youth, unable to engage in any "responsible" relationship.

If the problem of their bachelorhood can be considered manageable until they approach the symbolic barrier age of thirty, at which time they can hardly escape pressure from their families and friends to marry quickly, many participants quote still earlier limits like twenty-eight or even twenty-five. "Everyone would like their child to marry earlier," a father in a Beijing meeting told me. This emphasis on age is especially burdensome for women, who are seen as child-bearers and whose health and reproductive capacity as they age may be questioned by prospective families. ${ }^{6}$ Some consider unmarried women

\footnotetext{
${ }^{6}$ This invocation of biological constraints to justify focusing on age is not uniquely Chinese. In a Western context, Eva Illouz examined it as a result of a change in demographic and educational patterns, including the cultural association of the masculine ideal more with economic success than
} 
over thirty less desirable spouses due to worries that they will not be able to bear a child (see Hong Finscher 2014; Zurndorfer 2018).

The xiangqin gatherings give vivid testimony to these worries, since parents representing daughters outnumber those there for sons. Participants often highlight and exaggerate this disparity by insisting that two-thirds or even more of the children represented are women. In every situation where I counted, though, between 55 and 60 percent of the represented children were women (it never reached 60 percent). This context-specific social trend radically contradicts that observed by statisticians working at a national level, who emphasize the shortage of female births since the implementation of the birth control policy. According to their figures, the disproportion of male to female births should have led to a situation in which women found it easy to marry and many men were unable to find suitable partners. This was indeed the case in the countrysides, but not in the cities (Greenhalgh 2013). Gender-selected abortions biased against females mostly occurred in remote rural areas, and urban populations had less shifts in male/female birth rates. Today, it is in this latter context that middle-class women with higher levels of education, socially expected to marry a man of a social status equivalent to or greater than their own, encounter countless difficulties in finding a spouse. By contrast, their male counterparts can always marry a woman of a lower social status, or simply a younger one, and this in itself distorts the marriage market for women with high social and educational status.

\section{LOVE AND MATERIALISM}

At first sight, matchmaking practices seem to take into consideration only a set of criteria that correspond to what Chinese call the "tiaojian (conditions)" of the relationship. These are the means of living that will materially define the everyday quality of the future couple's life: their level of education, possession of an apartment, salary, and so forth. Any visitor to these parks sees many advertisement-like signs addressing mainly the physical and material conditions of the represented children, which make obvious the importance of possessing a higher socio-economic status. This is a feature common to all dimensions of the

\footnotetext{
fatherhood (2012: 74-78). In the context of the PRC's birth control policy and current birth-ratio, where most women only have one child, biology appears as a dubious justification for the pressures on women to marry young. In addition, though men feel these pressures much less, they are not exempt from them. They, too, are pushed to marry before thirty, and even if parents representing sons are only a minority, they were always well-represented in the marriage corners I attended. In the context of rural Korea, Clark Sorensen (2013 [1988]) examined the patterns of marriage and firstbirth ages as a result of fertility manipulation strategies that optimized the household ratios of the farm workforce. In this frame, having a child early could be seen as a way to optimize the (young) grandparents' capacity to support their grandchild's education. Grandparents' work in support of the younger generations is in fact a strong marker of the transformation of contemporary Chinese families (see Shen 2019). In the competitive and expensive urban Chinese environment, having a child when the grandparents are still young enough to provide everyday support seems economically wise, and this might help explain pressures to marry early.
} 
xiangqin phenomenon. Within China, xiangqin practices are often criticized for this overtly materialistic focus and the supposedly low priority they give to love. This is frequently framed as a national issue, calling into question the morality of the entire society. The desire to "marry up" without taking sentiments in account, associated with women of lower social backgrounds, attracts special critical attention. Nation-wide controversies have arisen over the materialistic ideals displayed by certain participants in matchmaking TV shows. Politically, these controversies led the state media administration (the Guangdian zongju, acronymized as SARFT in English) to impose tighter regulations in 2010 that required the shows to strictly control participants' behaviors and morality (see Kong 2013). Yet, in everyday society these same moral discourses were widespread long before they appeared on TV screens. "They want the fruits without having planted the tree," a female Beijing student told me in 2007, referring to fortune-oriented competitors.

When asked what criteria they use in seeking mates for their children, marriage corner parents often point to cultural justifications and quote old sayings such as "mendang hudui (households' characteristics should match appropriately)" to explain that they are looking for a duixiang, a marriage partner whose family will materially match their own. This homogamic standard is understood as morally acceptable in contrast with the indecency attributed to those accused of trying to enrich themselves through marriage. Other oft-quoted proverbs stress the secondary importance of personal feelings in marriage decisions. "Xian you mianbao, zai you aiqing (First the bread, then love)," goes one, while another states "pinjian fuqi baishi ai (Modest spouses will always endure sorrow)." Considering this, most people will present romantic love as less important than constructing an economically balanced family, and they perceive the search for a homogamous marriage as the only appropriate way to attain this.

Nevertheless, the material criteria of the search are frequently denounced even by participants. They declare that they have been imposed by the unbalanced nature of the economic and social situation and are the provisory outcome of an unstable development process that is putting their futures at risk. Some present this material approach as a non-choice, which they sometimes desperately regret but are forced to engage due to aggressive societal competition and the uncertainty of their family's future. A mother shared with me moving feelings of fear for her daughter of twenty-nine, who she was afraid would be unable to find a spouse. Sobbing, she justified her materialistic search in her daughter's name: "The problems we are confronted with are very practical. Today, people cannot just search for 'someone.' They have to find an income, an 'economy.' This is not only my daughter. The whole society works in that way." Her statement made clear that pragmatic, material criteria were given priority due to people's social situation. The domestic economy of the future couple and their dependents had to be considered thoroughly before making any decision. It is perhaps no surprise that it is divorced participants at xiangqin gatherings who most often voice vehement 
criticism of these practices and criteria. "In China, marriages are only a question of bank notes, cars, and houses! (piaozi, chezi, fangzi!)" one divorcee declared disdainfully at a Chengdu gathering in the spring of 2010. Others challenge such general statements, though many see them as commonsensical. Yet this commonsense is contested and perceived negatively. For this divorcee, as for many people of similar backgrounds, who often relate touching stories, the insufficient place given to romantic sentiment is the fundamental problem underlying Chinese current moral and matrimonial crisis.

The moral values implied by matchmaking practices are important to participants. The parents who I met in marriage corners often questioned the "level" of their interlocutors or other participants who, like them, were seeking a marriage partner, sometimes in a highly direct manner. Some vehemently doubted the moral standards of other parents, who they accuse of going "too far" or of unfairly forwarding only their own interests. Some, when first confronted with the casual nature of the search in the parks, expressed astonishment or disdain. One father in Beijing told me how he was taken aback that no one asked for traditional criteria such as the "eight signs (bazi)" of his son. ${ }^{7}$ "People are just asking about the conditions," he said, visibly shocked. In answer to these considerations many parents insist that, contrary to appearances, feelings are important to them and their children, but they worry about being deceived. A young secretary attending a Beijing gathering with her mother and a friend explained to me, "Being ill-intended [to others] is wrong, [but] guarding oneself [from others' ill-intentions] is imperative (hairen zhi xin buke you, fangren zhi xin buke wu)."

Put simply, in these settings, many parents, even those who partake in these meetings, explicitly reject the search's materialistic tendencies. Paradoxically, such criticisms come from the very people who are searching for their children's mates according to materialistic criteria. Though some youths and parents present the personal feelings as a secondary consideration to be addressed once the prospective couple meet, one more often hears the accusation that "some" ignore feelings completely. The notion of "feelings" (ganqing) that these parents raise transcends that of romantic love between spouses. It encompasses all the feelings that circulate between people, including the larger family, and explicitly includes their own parental affection for their child. Here, though, the emphasis is on individual feelings: "Parents look at the conditions, women want romanticism. It is too much for men," a Beijing mother lamented to me.

7 "Eight signs (bazi) horoscopy — a birthdate-based method that aims at predicting the fate of an individual - is one of the most widespread fate-prediction techniques in the Chinese world" (Homola 2021: 63). These signs were traditionally kept secret until marriage negotiations, during which they were exchanged in order to determine the compatibility of the two characters. According to younger interviewees in Beijing with whom I discussed the issue, internet and the wider availability of such data have rendered the tradition meaningless in the last decades. 
Such considerations, and the fact that the parental generation often appears to be in charge, might lead us to believe that marriage decisions involve no personal feelings, yet participants in matchmaking markets understand these criteria in the exact opposite way. To them, the criteria they use are a baseline to uphold moral standards and ensure that marriage decisions are not made according to materialistic considerations. They blame the material orientation of their matchmaking practices on those from lower social and economic backgrounds who, they claim, would marry up at any sentimental cost. Such assertions are often accompanied by justifications of the matchmaking practice as due to parental responsibility and love. Personal feelings here are the social medium of discrimination. Parents affectively evaluate and reject potential candidates in the name of love, both their love for their child and the pure love their child is looking for and no outsider should be allowed to cynically manipulate. This work they do for their child is seen to be part of a long-term affective exchange, reciprocated when their child takes care of them later in life. Searching for a mate for an aging child is not considered a pleasant task but is a familial duty. Parents often complain that they must accept the burden of helping their child find a spouse, even if they do so voluntarily or even without their child's consent. They point out how difficult the operation is and how they are forced to engage in it from fear of an uncertain future. These sorts of criticisms express the sentiment of vulnerability they confront.

The paradoxes involved here are key to understanding the moral dimensions of the xiangqin phenomenon. They reflect the on-going production of socio-cultural differences between the new urban middle classes and the new urban populations of rural origin.

\section{OUTSIDER WOMEN AND THE THREAT OF BLIND LOVE}

Criticisms of these matchmaking gatherings from within and within broader public discourses are directed at the ambitions of competitors referred to as "waidi nu (outsider women)." This is vague, in that different "outsiders" may be in quite different situations. Roberta Zavoretti showed how almost everyone refused to be labeled as a "peasant-worker," and how the discriminatory identification of outsiders was "fuzzy and contradictory." "Peasant workers" served more as a rhetorical figure to sustain the distinction of the urban middle-class (2017: 28). Here, too, we can observe a general discourse that generates differences with abstract "outsider women," the figure of which can serve to point up the high "quality" of one's own daughter. The frame within which these women are disqualified is a moral one: it is believed that they consider love less than do urban-educated women. They are said to use marriage as an unabashed means to climb the social ladder illegitimately, to attain an ideal life without effort. In the Chinese press, as in everyday discourse, one grasps the stigmatization of younger women from lower social backgrounds, who are 
accused of stealing the potential husbands of better-off women (see Zurndorfer 2018). This point is forwarded matter-of-factly in discussions between parents participating in marriage corners, marking it as an obvious justification for the attendance by so many parents of daughters.

The materialism ascribed to these "outsider women" is not the only justification for rejecting people coming from other regions. Another is outsiders lack a local hukou, the Chinese state's internal registration mediation of access to local social services, which depends on individuals' birthplaces or later-acquired rights (see Cheng and Selden 1994). This controversial system is used to regulate domestic migration by restricting the access rural populations have to medical, educational, and other services delivered to urban citizens. It sends them back to their places of origin when their presence in cities is considered undesirable. Controlling hukous is also a police measure. For example, when unemployment is too high in cities, they undertake waves of hukou control and use force to send "illegal" internal migrants back to where they came from, so as to relax the pressure on the city's job market. In one Beijing parental gathering I saw a mother put this criterion to the fore by mentioning, in red on the placard introducing her daughter, that she held a jing $h u$, a Beijing hukou. More often, this discriminatory criterion is only spoken of, justified by pragmatic criteria such as the great physical distance between two families that would, in the words of one father, render the life of the couple "too complicated." Beyond the administrative door-opener that the hukou serves as, others insist in a more general way on the difficulties of cooperation and cohabitation between people of different regional origins. They cite variations in dialectal languages and pronunciation, culinary habits, life habits (fengsu xiguan), or even regional rules of mahjong. Habits and geographical distance from their families are also invoked to reject students from Beijing universities who come from other provinces, even young people who are allowed a local hukou, since they were good enough to access the local universities, considered the best in the nation. Some parents explained it straightforwardly: "Beijing people 'look down upon (kanbuqi)' outsiders, and they are afraid of the complications that would occur if they had to host the [chosen spouse's] whole family." One does not encounter this rejection of outsiders only in the national capital; parents expressed similar concerns in the capital of Sichuan province, Chengdu.

One of the chief motives that participants ascribe to these criteria is the importance of feelings. Mr. Chen, a father from Chengdu, insisted that the main problem for highly educated daughters like his own is the city's shortage of young men. The situation is, he asserted, the result of a frantic competition imposed by the many poor young women who come to the city from villages or small towns desperate to survive and improve their living conditions. To them, he declared, the goal is not to find a working marriage but to secure a living and climb the social ladder. They need someone "to rely on (yikao)," and to find "a 
pot (guo)," that is to say, a reliable source of revenue to sustain them. Moreover, he said, men can always marry a younger woman of lower social status, while women cannot. The most educated urban women find themselves marginalized in the marriage market by less advantaged but younger competitors. Parents of daughters, like this man, often express resentment that lower-status women are usurping the place of their child. They insist their daughters want "romance," an ambivalent argument in China. The notion of "romanticism" embodies the imagery of Western romantic films and is made manifest in tokens of luxury such as expensive European-themed restaurants with candles and wine. Here, the romanticism that participating parents insist their daughters seek appears as a mode of social distinction of the self, a moral refinement that affirms the presence of a social barrier. This is pushed forward discursively, beyond the materialistic considerations that the middle- and upper-middle-class participating parents display. The process expresses disdain for less-privileged people who make marriage decisions in the light of day-to-day difficulties they face. It conveys the informal politics of social distinction at work within China.

The hypergynic marriage these parents denounce is in fact rare, as geographers Cindy Fan and Youqin Huang have found (1998). Chinese sociologist Zhang Yi has pointed out what is statistically observable: social homogamy (jieceng nei hun). Zhang comments, "If we accept the idea that everyone chose their spouse on the grounds of love, then we have to conclude that love's nature is structured by social classes (Ruguo shuo dajia dou yi aiqing wei jichu jiehun, name, aiqing jiushi "you jiejixing” de)" (2007: 67). This phenomenon is not unique to China, and the mechanism has been described by Pierre Bourdieu regarding France. He noted, "Taste is the form par excellence of amor fati" (1984: 244). That is to say, the personal inclination that presides over love at first sight, or charm, though experienced as fate, is not autonomous from one's socialization in one specific milieu and the individual habitus that results from it. Many sociological studies have established that "social class homogamy is largely a by-product of educational homogamy," and "educational homogamy is in part a by-product of matching of social origins" (Kalmijn 1998: 415). This has been observed many times, from the United States (e.g., Lipset 2015) to Korea (e.g., Baldacchino 2008), or Jordan (e.g., Adely 2016). Mate preferences and opportunities to meet with specific partners are interlinked. Romantic tastes are socially and historically shaped by the context in which people were raised and socialized.

The phantasmagoric threat of women of lower social background marrying up with men that these parents think of as prospective husbands reserved for their own daughters is considered real and shapes xiangqin in multiple ways. This idea is also widespread throughout the countryside from which China's neo-urban citizens come. Research on bachelors carried out by Han Hua in a village of Sichuan found that they, too, believe women from lower social backgrounds have opportunities to "marry up" (Han 2009: 60). This widely shared notion may 
be the result of mass media having publicized and disseminated these urban middle-class worries. Beyond its truth or falsity, the belief delineates a horizon of social hopes and anxiousness. It is either frightening or a hope-giving utopia of reversal of social inequalities through love. Better-off social milieus feel justified in working to prevent its realization. Signaling the dangers of love, a highincome woman of twenty-eight who I interviewed after meeting with her mother in a Beijing parental gathering told me, "Love is not the most important." Otherwise, she could just fall in love with "anyone," she insisted, before telling me what gap between her salary and that of a potential husband she would consider too wide. ${ }^{8}$ Still, when I asked her how she defined the notion of love she was invoking, she hesitated, before giving me the rather pragmatic definition of "a feeling that allows two people to support each other throughout life. Not necessarily through passion, but rather by bringing each other peace." At the same time, she expressed uncertainty about this definition, and added that she might see things differently later in life (also see Pettier 2018: 163). Here again, the meaning of love is unclear. The way this woman used and defined it vacillated. On one hand, love for her represented a danger, a passion that might happen with "anyone," and thus it cannot be the only criteria for selecting a partner. Yet she also put forward, even if only regarding the present, a dispassionate and pragmatic vision of a sensible relationship and the support it should provide. This rational approach to love is considered preferable and is accepted, but simultaneously doubted. I see this ambiguity of the definition of love in the contemporary Chinese urban context to be a key element in understanding the entire apparatus of the xiangqin phenomenon.

While romantic love rests largely on a process of idealizing the "love object" often described in the specialized socio-psychological literature, statistics make clear that, in real life, love is rarely as socially blind as lovers like to describe it. In China, these ambiguities and contradictions were characterized by research showing, for example, that some newlywed couples who claimed to have been in love with their spouse on their wedding day had "never" or "rarely" met each other prior to that day (see Whyte 1990: 187). In the last decade, further research has found that young people granted much importance to seemingly opposed dimensions of the marriage relationship, like the intimacy between lovers and parental weight in choosing spouses (see Jankowiak 2013: 208-9), or material dimensions and romantic sentiments (see Jankowiak et al. 2015: 428). This understanding of love does not rest solely on individual feelings but also considers wider social and material dimensions. Nonetheless, studies carried out in cultural contexts outside of China regularly find that lovers typically choose sociologically appropriate partners, approximately equal in terms of both education and wealth. One needs not be cynical to understand this. As Bourdieu showed through his use

${ }^{8}$ Baldacchino (2008) has examined a similar case in contemporary Korea. 
of the notion of habitus, this is the result of practice. The lovers are likely to fall in love with people who visit the same places as they do and with whom they share common tastes and practices. Therefore, lovers tend to share a lot of social characteristics, from education to economic and cultural background, which relegates marriage to another cultural mechanism of the reproduction of social class. This is indeed not how the process is experienced initially. Following self-conscious calculations or not, falling in love is seen as fate. This point is equally valid in China, where references to yuanfen, or predestined affinity, are ubiquitous in talk about love. In the case considered here, however, an interesting twist happens: the two dimensions of love - as a practice and as an ideal - do not coalesce. The first is not innocently hidden behind the second; both are acknowledged, and they exist in opposition. As in the words of the young woman quoted earlier, love is "blind" to social differences, and thus dangerous, but love can also be a pragmatic, day-to-day sentiment that supports everyday life.

The notion that love is dangerous has been discussed before in the anthropology of China. Sulamith Potter thought that love was rejected in rural China because it could disturb the order of existing social networks and structures (1988: 199). This interpretation attracted numerous comments and criticisms based on varying views that love does or does not have a specific place in the organization of Chinese social life. Andrew Kipnis adopted the opposing view in describing how feelings are at the core of the entire networking system within Chinese society (1997: 109). Joan and Arthur Kleinman criticized the Orientalist stance they read in Potter's position and emphasized individual testimonies to argue for the importance of feelings in China (1991: 286). Finally, Yan Yunxiang rejected both Potter's and Kipnis' interpretations as overly systemic and for leaving too little room for the capacity of young Chinese people to change and adapt (Yan 2003: 83). The case here turns this debate on its head. Rather than China being a society organized against love, as Potter thought, or around feelings, as Kipnis argued, or moving in a flexible individualized way, as Yan portrayed in the northern Chinese countryside, here we see how a specific social milieu —urban middle-classes - works to prevent potential excesses of love in the name of romantic love itself. Parents control who their child marries in order to preclude outsiders manipulating their sentiments.

The idea that love is blind has a discernible impact in everyday understandings of reality. Two days after Mr. Chen gave me his analysis, I met with a friend named Cheng Yu, a Sichuanese woman of twenty-two who herself came from a small town and who I had met and sympathized with at the Chengdu bike shop where she worked. ${ }^{9}$ I asked for her opinion of Mr. Chen's comments that women of rural origin like her needed to find a "pot" to

${ }^{9}$ All the names of people I met in the field are pseudonyms. 
guarantee their future. She found the idea and expression hilarious and began laughing wholeheartedly. In a picturesque and joyful fashion, she said she would be pleased to find herself such a "pot," and, still laughing, began enumerating the treasures it could contain. "There is a bit of everything in these pots," she claimed jokingly, "luxury cars, mansions, international trips, ingots of gold, fantastic restaurant meals... That is what such a pot would contain." Cheng Yu was an interesting character, simple and straightforward in her expressions, manners, and attitudes. She was a working girl who had just arrived in Chengdu and was above all a person critical of the social and political atmosphere of her country. This young, modest, and hardworking woman had never appeared to me until that point as someone looking for a husband, so the fact that she talked this way, suggesting a desire for enrichment through marriage, even in a joking way, seemed significant. She communicated the same fantasy of "making it" and competition that made so many of the parents I was meeting at the xiangqin gatherings worry for their daughters. Having met Cheng Yu soon after her arrival in Chengdu allowed me to see her evolution over time. Across her first six months of city life, she progressively transformed herself. Little by little, she adopted manners and clothes that fit more conventional stereotypes of femininity, and she began wearing makeup. Extraverted attitudes, like laughing out loud, progressively disappeared from her repertoire, and she adopted more reserved, delicate, and sophisticated gestures. A few months later she left her bike shop job for one at a place where she sold wine, and by then her physical transformation was already striking. None of these transformations implied an elaborate strategy to marry up; they rather expressed her progressive conversion to the norms of femininity that dominated in Chengdu. She was doing exactly what is demanded from other citizens who arrive from remote areas: "civilizing" by adopting the mores and manners of Chinese urban society. Even if these changes were not consciously tactical, she began to embody the characteristics Mr. Chen spoke of as "threats" to the marriageability of his daughter, making her conversion potentially suspicious.

\section{PERSONAL AMBITIONS AND SOCIAL INEQUALITIES}

Cases of young people of modest means being rejected due to their social origin were common during my research. While, as we have seen, women tended to be rejected on moral grounds, men were most explicitly rejected on the basis of their modest economic means. One of them was $\mathrm{Zhang} \mathrm{Li}$, a young computer specialist in Chengdu from a peasant family of Leshan in Sichuan province. Zhang Li had earned a bachelor's degree at a Chengdu-based university but was uninterested in programming and did not want to sit in front of a computer all day. He wanted a job that would let him interact more with people. When we first met in 2008, Zhang had already left his previous job to pursue a career as an English translator. The diligent twenty-four-year-old then became involved in a romantic relationship with a young woman from a family in Chengdu. Her father was a 
banker, and her family was preparing to send her to complete her education in Canada. This was impossible for Zhang $\mathrm{Li}$, whose advanced level of English could not compensate for his modest bank account. He often discussed this economic gap with his friends, who all opined that this obstacle was insurmountable and would inevitably end their relationship. His girlfriend, still living with her parents, had to stay away from him most of the time so her father would not suspect that they had a relationship.

Zhang Li also did not want to see her too much because he was ashamed of his poor economic status and his inability to take her out on dates. As an English language teacher his monthly wage was 2000 yuan, double the salary of many manual workers at the time, but barely enough to live in a city like Chengdu. To save on housing costs he had since completing his studies retained his student apartment, a small, elongated room almost entirely filled by his bed. Living in this confined space in which he spent so much of his time required a daily routine of moving his things from the bed to the floor when he needed to sleep, and then back onto the bed when he woke up. As a point of comparison, his cousin, a flight attendant for a local company who I had first befriended in a bookstore, was making two to three times more money. The cousin had bought his own apartment, which was large enough to host me for several weeks in my own bedroom.

Zhang Li was continuously studying English through his own means and was lonely most of the time. He seemed to be under considerable pressure. After we had met a few times he told me of his ambitions and said that he could not be nor feel respectable until he had achieved his goals. Denigrating the work that men of his age did, such as the waitstaff in the little restaurant we were eating in, this son from a poor family said it was impossible for a man with such a job to find a girlfriend since such lowly positions bore too much shame, making it impossible even to think about establishing contact with any pretty woman. In the end, his efforts to prove his worth failed to secure him this girlfriend. Wanting to bring their relationship out of the closet, she first introduced him to her mother, with whom he had a long discussion about their future as a couple. "It went very well, I think that she supported me after that," he told me. However, his hopes were soon dashed. The next step was for him to meet the girl's father, but he proved unwilling to give him a chance. Once informed of Zhang Li's background and presented with a photo of him, he simply told her to leave him, and she obeyed. Zhang Li had no way to prove his worth to the father of the woman he loved.

The following months were bitter for the two separated lovers. At first, she rejected his attempts to reinitiate the contact, before suddenly insisting on meeting him and coming unannounced to his place on Valentine's Day a few weeks later. Having anticipated that such a meeting might occur and knowing that it would be a risky day for both of them, Zhang Li was not home when she arrived. He had fled to a friend's place to prevent the meeting. Still, a few weeks 
later, a month before her departure to Canada, I found him bitterly questioning himself on whether to send her a present for her forthcoming birthday. This melancholic situation lasted a few months until Zhang Li secured a position at an international North American company and was sent to work in India for six months. This period helped him to recover from his heartache, and after his return from India he began dating again. In the following years he married, became a father, and effectively reached his ambitions by becoming a higherlevel manager for the same international company in Shenzhen.

\section{ROMANTIC LOVE AND THE SOCIAL COMPETITION}

In the cases I have presented here one can observe how to insist on the importance of love may in some cases be socially disqualifying. After all, anyone with a lower-level socio-economic background like Cheng Yu or Zhang Li may be perceived to be marrying someone for purely material reasons, even if they would adamantly deny that. One interesting dimension these two cases reveal is the gendered character of this moral economy. While it would be simplistic to say that outsider men are rejected only on material grounds and outsider women only on moral ones, this gendered difference is a prominent feature of how the domain of love discriminates against them. That said, the end results are surprisingly similar: both are rejected at first glance, even before they are personally known. They are offered no chance to express or defend their sentiments, which are given no serious consideration. Their rejection is somewhat automatized, and the "outsider" label attributed to them is disqualifying. Granting importance to sentiments does not protect them from suspicions or accusations that they are marrying for money rather than love. There is no way for them to prove the true character of their feelings, and so they may always be accused of cheating in the game.

While the idealization of "true love" has been shown to protect modest men from the threat of losing their partner on material grounds in some countries, like Tanzania (Stark 2017) or Jordan (Nasser El-Dine 2018), financial precarity was identified as a threat to men's position in post-socialist Cuba (Härköne 2018). The Chinese context appears to be more in line with the latter case. But these studies were all carried out among urban groups of modest means, while the present case examines the rejection of lower economic groups identified as "outsiders" by groups of people benefiting from comparatively privileged socio-economic conditions. What is striking here is the way this social discrimination plays itself out. The love politics here go beyond the notion of a "politics of sentiments" (Abu-Lughod 1990). This situation does not only concern love but is also working through and with "love." The ganqing expressed by the parents is a form of love that encompasses the feelings of the larger family. When middle-class parents worry for their daughters, we cannot say that they are giving importance to feelings merely to mask not wanting their 
daughters to marry "down." Rather, like more modest people, they, too, must deal with their position within the social world and with the difficulties they face. They, too, feel anxious about the future and their ability to maintain their social standing. They worry about the conditions they will live in when they are older, and especially that they might have to rely on a single child who has entered a bad marriage, thereby putting the whole family at risk.

We can only understand the ethical controversies surrounding love in present-day China as they fit within the social and economic system. It is a system within which fantasies of extreme enrichment and fears of social downfall work hand in hand, and questions of love appear rather instrumental (see Farrer and Sun 2003: 14-16; Osburg 2013: 171). Still, instrumental as it may be, to claim that a socially discriminating politics of love is ongoing through these moral debates is not to accuse those who insist that feelings are important of fraud. To exclude the socially disadvantaged is not these parents' aim, per se. Rather, it is an unintended consequence of their desire for security. This class politics works through sincere sensibilities.

That does not absolve the marriage corners' participants of the segregating effects of the choices they make - their attitudes are not simply unconscious habitus. Their exchanges and the moral arguments they discuss together, or with me, make clear that they are conscious of the discriminatory effects. Indeed, that is what xiangqin is all about: choosing marriage partners and securing better future as a result of one's choices. This moral process is considered a reasonable way to make their selections, and their self-awareness of it brings further questions to the debate. Throughout the last decade, much research on China has emphasized that people are questioning whether a "moral crisis" is ongoing (see Kipnis 2016; Steinmüller and Wu 2011; Yan 2009; 2012; 2014). The examples I have provided here allow us to side-step this and look at what the question of a moral crisis implies.

The accusations that segments of society are discounting love come from better-off segments of the population against those in more severe situations. This appears to be a fundamental mechanism of the process of reconfiguring social class in post-Maoist society. These allegations are a sentimental, moral justification of the segregating practices inherent in xiangqin. They justify parental control of the spouse selection process by constructing it as a moral necessity. There can be no xiangqin without disputes over love, and thus social discrimination. There can be no xiangqin without the frightening figure of the poor villager ready to betray love in order to ensure his or her future. These reinvented forms of marriage presentation embody the strategies employed by new urban middle-classes' to secure their positions within society.

We can contrast this phenomenon with the notion of emotional capital Western middle- and upper-classes use to distinguish themselves, as studied by Illouz (2008), and with what, in the context of Egypt, Aymon Kreil 
termed "love scales" - "a hierarchy of registers in interactions with girls and women, which is seen as connected to an individual's capacity for linguistic expression" (2014: 88). Such phenomena also exist in China, as seen in the demand for sentimental expression described by Yunxiang Yan (2002) in the context of the rural northeast of the 1990s, or the intense development of psychotherapy in China over the last decade (Zhang 2020). The crucial point here is not that the capacity of less privileged groups to express emotions would be questioned, but that when they do it is greeted with suspicion. More than the form of the emotional expression, it is its credibility that is doubted, and this doubt is based on material grounds. To use Viviana Zelizer's vocabulary (2005), Chinese parents produce an original separation of the material and sentimental spheres by supervising the first while leaving children the responsibility for the second. Nonetheless, their engagement also reflects the interconnectivity of the two dimensions, this time regarding outsiders, whom parents reject on material grounds but in the name of love. The profoundly renewed mode of mate choice in xiangqin practices exhibits the extent to which the intimate politics of marriage and love must be understood in their larger social context. These ongoing moral controversies in an economically aggressive, competitive society show how personal affect and the questions of morals cannot be dissociated from their larger historical and economic setting.

The most novel dimension of this love complex is how it has been assimilated into the family realm, against which the notion of romantic love was initially formulated, since independent choice of a partner was an emancipation from family politics. This may be because "the family factor is very important in the Chinese case ... because the Chinese personhood is first and foremost defined by and constructed through family relationships," as Li Tian and Yunxiang Yan observed (2019: 109). Paradoxically, it should be noted that this split of responsibilities and the search for an intergenerational consensus regarding mate choice may allow for a stronger idealization of the notion of romantic love in China than in places where both dimensions are left to the whims of lovers. Yet, this idealization may also make the notion of love appear unreachable on earthly grounds, relegating it to a theoretical or dreamy ideal. This may be why many parents and bachelors I interviewed so often stressed that they believe love is given short shrift in their society. A last dimension of this phenomenon is that the strong idealization of love allowed by the delegation of its rational dimensions to third parties may turn romantic love into a source of hope for youth. Studies in recent decades have often stressed the social, economic, and psychological constraints on urban middleclass young people (see Bregnbæk 2016; Fong 2004; Xu 2017). The ideal of an unreachable romantic love may provide some of them with an imaginary world to escape to. 
A NEW MORAL ECONOMY OF LOVE

How specific is this model to China? The conditions of the population I have worked with are characterized by two elements. First, there has been a drastic reduction in family size due to state-backed family planning. Second, social and economic competition is strongly reinforced among the newly formed middle and upper-middle urban classes. Together, these have strengthened the intergenerational material and affective interdependency within the family, as well as the emphasis put on individual characteristics, intimacy, and sentiments between marriage partners. This limits this moral economy of love and the associated distribution of the power to make marriage decisions to one segment of the Chinese population, but it also opens up the possibility of finding similar moral economies in comparable situations of intensified individual competition and reduced family sizes. One last important element is that the Chinese modernization process, as in other places, was constrained by a confrontation with a European model that made the notion of love, and the emphasis modernization thinkers of the time put on it, mysterious. This imported notion of love is an idealized one, and this led to political controversies, which among Chinese urban middle classes, have been resolved by separating love's two dimensions. This model declares romantic love to be central while retaining a traditional emphasis put on intra-familial solidarity. The omnipresence of xiangqin practices and the controversies encircling them, as well as the neo-familism observed by Yan Yunxiang (2018), reveal that this model has in China gained a normalcy not previously observed.

"Only the very privileged have ever believed in marriage based only on mutual affections," the historian John Gillis once observed (1985: 4). One might say instead that only the very privileged could believe that it is what they were actually pursuing, as opposed to less-romantic agendas. The cases presented here reveal ways in which moralities and material ideals are interrelated. Parents' materialistic criteria go hand in hand with their fears about an uncertain future and their paradoxical insistence on the importance of feelings. Cheng Yu and Zhang Li know that, despite their best efforts, they are perceived as crassly seeking to "marry up." The debates surrounding xiangqin display the new moral horizon of China, and how the tendency toward a greater social and moral distinction of the self is shaping and justifying the persistence and extension of material inequality.

The articulation of political questioning of romantic love and the traditional practice of arranged marriage in a reinvented form of intergenerational matchmaking is a key dimension of the re-stratification of post-Maoist society along socioeconomic and moral lines. The older racial and cultural questions of romantic love have been reframed as a classist one, in ways that reflect the stratified nature of contemporary society. As capitalist social classes rapidly restructure, love sits at the locus of articulation of new morals of social and 
cultural differentiation for the new generations. Love acts as a tool to consolidate and justify inequalities by giving them a moral grounding. It builds bridges between certain families and digs canyons between others. Yet this is not the only role it plays: the high level of idealization of love here means elders must protect youth from the "blindness" of their own sentiments. In this way, Chinese middle-class families not only ensure their own social reproduction, but they uphold their own indispensability to their children, while acknowledging and even highlighting the importance of their individual sentiments.

Returning to the sentence with which I began this article- "I don't know what love is"- - we can now grasp how it expresses this complexity. It speaks to the unavoidable character of the topic, as my interlocutors feel the need to situate themselves vis-à-vis love despite its perceived blurred sense and undefined limits. It accentuates love's relationship with the idealistic fantasy of modernity, and reveals people's efforts to reach that ideal, and the difficulties they confront in their quest.

\section{REFERENCES}

Abu-Lughod, Lila. 1990. Shifting Politics in Bedouin Love Poetry. In Catherine Lutz and Lila Abu-Lughod, eds., Language and the Politics of Emotion. Cambridge and Paris: Cambridge University Press and Éditions de la Maison des Sciences de l'Homme, 24-45.

Adely, Fida. 2016. A Different Kind of Love: Compatibility (Insijam) and Marriage in Jordan. Arab Studies Journal 24, 2: 102-27.

Baldacchino, Jean-Paul. 2008. Eros and Modernity: Convulsions of the Heart in Modern Korea. Asian Studies Review 32: 99-122.

Beall, Anne E. and Robert J. Sternberg. 1995. The Social Construction of Love. Journal of Social and Personal Relationships 12, 3: 417-38.

Bisetto, Barbara. 2012. Fragments of Qing 情: The Qingshi leilüe 情史類略 and the Literary Categorization of 'Love' in the 17th Century China. In Giusi Tamburello, ed., Concepts and Categories of Emotion in East Asia. Roma: Carocci, 164-75.

Bourdieu, Pierre. 1984[1979]. Distinction: A Social Critique of the Judgement of Taste. Cambridge: Harvard University Press.

Bourdieu, Pierre. 2008[2002]. The Bachelors 'Ball: The Crisis of Peasant Society in Béarn. Cambridge: Polity Press.

Bregnbæk, Susanne. 2016. Fragile Elite: The Dilemmas of China's Top University Students. Stanford: Stanford University Press.

Butel, Jean-Michel. 2011. Des couples aimants pour une nation moderne: un nouveau modèle familial dans le Japon de la fin du XIXème siècle. In Christian Galan and Emmanuel Lozerand, eds., La famille japonaise moderne (1868-1926), Discours et débats. Arles: Éditions Philippe Picquier, 361-78.

Chen, Siyu. 2016. Disciplining Desiring Subjects through the Remodeling of Masculinity: A Case Study of a Chinese Reality Dating Show. Modern China 43, 1: 93-120.

Cheng, Tiejun and Mark Selden. 1994. The Origins and Social Consequences of China's Hukou System. China Quarterly 139: 644-68. 
Croll, Elisabeth. 1981. The Politics of Marriage in Contemporary China. Cambridge: Cambridge University Press.

De Munck, Victor, Andrey Korotayev, and Darya Khaltourina. 2009. A Comparative Study of the Structure of Love in the U.S. and Russia: Finding a Common Core of Characteristics and National and Gender Differences. Ethnology 48, 4: 337-57.

De Munck, Victor, Andrey Korotayev, Janina de Munck, and Darya Khaltourina. 2011. Cross-Cultural Analysis of Models of Romantic Love among U.S. Residents, Russians, and Lithuanians. Cross-Cultural Research 45, 2: 128-54.

De Rougemont, Denis. 1983[1940]. Love in the Western World. Princeton: Princeton University Press.

Diamant, Neil. 2000. Revolutionizing the Family: Politics, Love, and Divorce in Urban and Rural China. Berkeley: University of California Press.

Domenach, Jean-Luc and Chang-Ming Hua. 1987. Le Mariage en Chine. Paris: Presses de la Fondation nationale des sciences politiques.

Edwards, Walter. 1989. Modern Japan through Its Weddings: Gender, Person, and Society in Ritual Portrayal. Stanford: Stanford University Press.

Fan, Cindy and Youqin Huang. 1998. Waves of Rural Brides: Female Marriage Migration in China. Annals of the Association of American Geographers 88, 2: 227-51.

Farrer, James and Sun Zhongxin. 2003. Extramarital Love in Shanghai. China Journal 50: $1-36$.

Fassin, Didier. 2009. Moral Economies Revisited. Annales. Histoire, Sciences Sociales 64, 6: 1237-66.

Finck, Henry T. 1899. Primitive Love and Love-Stories. New York: Charles Scribner.

Fong, Vanessa. 2004. Only Hope: Coming of Age under China's One-Child Policy. Stanford: Stanford University Press.

Gillis, John R. 1985. For Better, For Worse: British Marriages, 1600 to the Present. Oxford: Oxford University Press.

Goody, Jack. 2006. The Theft of History. Cambridge: Cambridge University Press.

Greenhalgh, Susan. 2013. Patriarchal Demographics? China's Sex Ratio Reconsidered. Population and Development Review 38: 130-49 (supplement, "Population and Public Policy: Essays in Honor of Paul Demeny").

Greenhalgh, Susan and Edwin A. Winckler. 2005. Governing China's Population, from Leninist to Neoliberal Biopolitics. Stanford: Stanford University Press.

Han, Hua. 2009. Living a Single Life: The Plight and Adaptation of the Bachelors in Yishala. In Susanne Brandtstädter and Gonçalo D. Santos, eds., Chinese Kinship: Contemporary Anthropological Perspectives. London: Routledge, 48-66.

Härköne, Heidi. 2018. Money, Love, and Fragile Reciprocity in Contemporary Havana, Cuba. Journal of Latin American and Caribbean Anthropology 24, 2: 370-87.

Hirsch, Jennifer and Holly Wardlow, eds. 2006. Modern Loves: The Anthropology of Romantic Courtship and Companionate Marriage. Ann Arbor: University of Michigan Press.

Homola, Stéphanie. 2021. Chinese Eight Signs Prediction: Ontology, Knowledge, and Computation. Social Analysis 65, 2: 62-81.

Hong Fincher, Leta. 2014. Leftover Women: The Resurgence of Gender Inequality in China. London: Zed Books.

Huang, Martin W. 1998. Sentiments of Desire: Thoughts on the Cult of Qing in Ming-Qing Literature. Chinese Literature: Essays, Articles, Reviews (CLEAR) 20: 153-84. 
Illouz, Eva. 1997. Consuming the Romantic Utopia, Love and the Cultural Contradiction of Capitalism. Berkeley: University of California Press.

Illouz, Eva. 2008. Saving the Modern Soul: Therapy, Emotions, and the Culture of SelfHelp. Berkeley: University of California Press.

Illouz, Eva. 2012. Why Love Hurts: A Sociological Explanation. Cambridge: Polity Press. Jankowiak, William, ed. 1995. Romantic Passion: A Universal Experience? New York: Columbia University Press.

Jankowiak, William. 2013. Chinese Youth: Hot Romance and Cold Calculation. In Perry Link, Richard P. Madsen, and Paul G. Pickowicz, eds., Restless China. Lanham: Rowman \& Littlefield, 189-210.

Jankowiak, William, Yifei Shen, Shiyu Yao, Cancan Wang, and Shelly Volsche. 2015. Investigating Love's Universal Attributes: A Research Report from China. Cross-Cultural Research 49, 4: 422-36.

Kalmijn, Matthijs. 1998. Intermarriage and Homogamy: Causes, Patterns, Trends. Annual Review of Sociology 24: 395-421.

Kendall, Laurel. 1996. Getting Married in Korea: Of Gender, Morality and Modernity. Berkeley: University of California Press.

Kim, Chiyoung. 2013. The Conceptual History of 'Yŏnae' (Love) in the Korean Colonial Period. Acta Koreana 16, 1: 113-40.

Kim, Choong Soon. 1974. The Yon'jul-hon or Chain-String Form of Marriage Arrangement in Korea. Journal of Marriage and Family 36, 3: 575-79.

Kipnis, Andrew B. 1997. Producing Guanxi: Sentiment, Self, and Subculture in a North China Village. Durham: Duke University Press.

Kipnis, Andrew B. 2016. Modernity and the Chinese Moral Crisis (Review Essay). China Journal 75: 121-27.

Kleinman, Arthur and Joan Kleinman. 1991. Suffering and Its Professional Transformation: Toward an Ethnography of Interpersonal Experience. Culture, Medicine, and Psychiatry 15, 3: 275-301.

Kong, Shuyu. 2013. Are You the One? The Competing Public Voices of China's Post1980s Generation. In Perry Link, Richard P. Madsen, and Paul G. Pickowicz, eds., Restless China. Lanham: Rowman \& Littlefield, 127-47.

Kreil, Aymon. 2014. Love Scales: Class and Expression of Feelings in Cairo. La Ricerca Folklorica 69: 83-91.

Kwon, Boduerae. 2005. The Paradoxical Structure of Modern "Love" in Korea: Yeonae and Its Possibilities. Korea Journal 45, 3: 185-208.

Lee, Haiyan. 2007. Revolution of the Heart: A Genealogy of Love in China, 1900-1950. Stanford: Stanford University Press.

Lee, Leo Ou-fan. 1973. The Romantic Generation of Modern Chinese Writers. Cambridge: Harvard University Press.

Li, Luzhou. 2015. If You Are the One: Dating Shows and Feminist Politics in Contemporary China. International Journal of Cultural Studies 18, 5: 519-35.

Lindholm, Charles. 1998. Love and Structure. Theory, Culture \& Society 15: 243-63.

Lipset, David. 2015. On the Bridge: Class and the Chronotrope of Modern Romance in an American Love Story. Anthropology Quarterly 88, 1: 163-86.

Liu, Jianmei. 2003. Revolution Plus Love: Literary History, Women's Bodies, and Thematic Repetition in Twentieth-Century Chinese Fiction. Honolulu: University of Hawai`i Press. 
Liu, Lydia H. 1995. Translingual Practice: Literature, National Culture, and Translated Modernity - China, 1900-1937. Stanford: Stanford University Press.

Liu, Xin. 2000. In One's Own Shadow. An Ethnographic Account of the Condition of Post-Reform Rural China. Berkeley: University of California Press.

Luhmann, Nikkas. 2010. Love: A Sketch. Cambridge: Polity Press.

MacFarlane, Alan. 1987. The Culture of Capitalism. Oxford: Blackwell.

Marr, David G. 1981. Vietnamese Tradition on Trial, 1920-1945. Berkeley: University of California Press.

Morton, Leith. 1997. The Concept of Romantic Love in the Taiyō Magazine 1895-1905. Japan Review 8: 79-103.

Nasser El-Dine, Sandra. 2018. Love, Materiality, and Masculinity in Jordan: "Doing" Romance with Limited Resources. Men and Masculinities 21, 3: 423-42.

Nelson, Alex J. and Kyu Jin Yon. 2018. Core and Peripheral Features of the CrossCultural Model of Romantic Love. Cross-Cultural Research 53, 5: 447-82.

Nguyễn, Văn Ký. 1995. La société vietnamienne face à la modernité: Le Tonkin de la fin du XIXème siècle à la seconde guerre mondiale. Paris: L'Harmattan.

Osburg, John. 2013. Anxious Wealth. Money and Morality among China's New Rich. Stanford: Stanford University Press.

Padilla, Mark et al., eds. 2007. Love and Globalization. Transformation of Intimacy in the Contemporary World. Nashville: Vanderbilt University Press.

Palomera, Jaime and Theodora Vetta. 2016. Moral Economy: Rethinking a Radical Concept. Anthropological Theory 16, 4: 1-21.

Pettier, Jean-Baptiste. 2016. The Affective Scope: Entering China's Urban Moral and Economic World through Its Emotional Disturbances. Anthropology of Consciousness 27, 1: 75-96.

Pettier, Jean-Baptiste. 2017. La fatalité des meiren: Usages de l'histoire des marieuses traditionnelles comme justification à l'intermédiation matrimoniale en Chine contemporaine. Études Chinoises 36, 1: 79-103.

Pettier, Jean-Baptiste. 2018. Ambivalences affectives: Le critère sentimental dans le choix du conjoint en Chine urbaine contemporaine. In Catherine Capdeville and Delphine Ortis, eds., Les institutions de l'amour: Cour, amour, mariage. Enquêtes anthropologiques en Asie et dans l'océan Indien. Paris: Presses de l'Inalco, 155-79.

Pettier, Jean-Baptiste. 2019. The Reinvention of Matchmakers: Ethnography of a Marriage Agency in Urban China. L'Homme 229: I-XXII.

Pettier, Jean-Baptiste. 2020. Marrying the Perfect Child: Middle Class Norms and Intergenerational Arrangements in the Marriage Corners of Urban China. Ethnography: 1-22. https://journals.sagepub.com/doi/full/10.1177/1466138120960512.

Phinney, Harriet M. 2008. Objects of Affection: Vietnamese Discourses on Love and Emancipation. Positions: East Asia Cultures Critique 16, 2: 333-35.

Piquet, Hélène and André Laliberté. 2020. La réactivation "par le haut" de la tradition de piété filiale en Chine: enjeux et défis. Droit et société 105: 407-28.

Potter, Sulamith Heins. 1988. The Cultural Construction of Emotion in Rural Chinese Social Life. Ethos 16, 2: 181-208.

Reddy, William. 2012. The Making of Romantic Love: Longing and Sexuality in Europe, South Asia, and Japan, 900-1200 CE. Chicago: University of Chicago Press.

Ryang, Sonia. 2006. Love in Modern Japan: Its Estrangement from Self, Sex and Society. New York: Routledge. 
Shen, Yifei. 2019. Shei zai ni jia: Zhongguo "geti jiating” de xuanze [Who is your family: the choice of China's "iFamilies"]. Shanghai: Sanlian Bookstore Co.

Smith, Arthur H. 1894. Chinese Characteristics. New York: Fleming H. Revell Co.

Sorensen, Clark. 2013[1988]. Over the Mountains Are Mountains: Korean Peasant Households and Their Adaptations to Rapid Industrialization. Seattle: University of Washington Press.

Stark, Laura. 2017. Cultural Politics of Love and Provision among Poor Youth in Urban Tanzania. Ethnos 82, 3: 569-91.

Steinmüller, Hans and Fei Wu. 2011. School Killings in China: Society or Wilderness? Anthropology Today 27, 1: 10-13.

Sun, Peidong. 2012. Shei lai qu wode nü'er? Shanghai xiangqin jiao yu 'baifa xiangqin' [Who wants to marry my daughter? Shanghai's matchmaking corner and the "grey hair marriage market"]. Beijing: China Social Sciences Press.

Suzuki, Michiko. 2010. Becoming Modern Women: Love and Female Identity in Prewar Japanese Literature and Culture. Stanford: Stanford University Press.

Tian, Li and Yunxiang Yan. 2019. Self-Cultivation of the Socialist New Person in Maoist China: Evidence from a Family's Private Letters, 1961-1986. China Journal 82: 88-110.

Wei, Luo and Zhen Sun. 2014. Are You the One? China's TV Dating Shows and the Sheng Nü's Predicament. Feminist Media Studies 15, 2: 239-56.

Whyte, Martin King. 1990. Changes in Mate Choice in Chengdu. In Deborah Davis and Ezra F. Vogel, eds., Chinese Society on the Eve of Tiananmen. Cambridge: Harvard University Press, 181-213.

Wynn, L. L. 2015. Writing Affect, Love, and Desire into Ethnography. In Kalpana Ram and Christopher Houston, eds., Phenomenology in Anthropology: A Sense of Perspective. Bloomington: Indiana University Press, 224-47.

$\mathrm{Xu}$, Jing. 2017. The Good Child: Moral Development in a Chinese Preschool. Stanford: Stanford University Press.

Yan, Yunxiang. 2002. Courtship, Love and Premarital Sex in a North China Village. China Journal 48: 29-53.

Yan, Yunxiang. 2003. Private Life under Socialism, Love, Intimacy, and Family Change in a Chinese Village, 1949-1999. Stanford: Stanford University Press.

Yan, Yunxiang. 2009. The Good Samaritan's New Trouble: A Study of the Changing Moral Landscape in Contemporary China. Social Anthropology 17, 1: 9-24.

Yan, Yunxiang. 2012. Food Safety and Social Risk in Contemporary China. Journal of Asian Studies 70, 3: 705-29.

Yan, Yunxiang. 2014. The Moral Implications of Immorality: The Chinese Case for a New Anthropology of Morality. Journal of Religious Ethics 42, 3: 460-93.

Yan, Yunxiang. 2018. Neo-Familism and the State in Contemporary China. Urban Anthropology and Studies of Cultural Systems and World Economic Development 47, 3 \& 4: 181-224.

Zavoretti, Roberta. 2017. Rural Origins, City Lives. Seattle: University of Washington Press.

Zelizer, Viviana. 2005. The Purchase of Intimacy. Princeton: Princeton University Press.

Zhang, Everett Yuehong. 2005. Rethinking Sexual Repression in Maoist China: Ideology, Structure and the Ownership of the Body. Body and Society 11, 3: 1-25. 
Zhang, Jun and Peidong Sun. 2014. "When Are You Going to Get Married?" Parental Matchmaking and Middle-Class Women in Contemporary Urban China. In Deborah S. Davis and Sara L. Friedman, eds., Wives, Husbands, and Lovers: Marriage and Sexuality in Hong Kong, Taiwan, and Urban China. Stanford: Stanford University Press, 118-44.

Zhang, Li. 2020. Anxious China: Inner Revolution and Politics of Psychotherapy. Oakland: University of California Press.

Zhang, Yi. 2007. Zhongguo jieceng nei hun zhi de yanxu [Continuation of the same-class marriage system in China]. Family Studies / Zhongguo Jiating Yanjiu 2: 56-69.

Zigon, Jarett. 2014. On Love: Remaking Moral Subjectivity in Postrehabilitation Russia. American Ethnologist 40, 1: 201-15.

Zurndorfer, Harriet. 2018. Escape from the Country: The Gender Politics of Chinese Women in Pursuit of Transnational Romance. Gender, Place \& Culture 25, 4: 489-506.

\begin{abstract}
Chinese practices of matchmaking have been controversial for over a century. Their continued transformations reveal a complex nexus of sentimental and material dimensions in the marriage-decision process at the heart of the negotiations between families and in their selections of proper candidates. This interplay between personal sentiments, concrete considerations, and the desire for success makes marriage controversial, as "love" is claimed and proclaimed at the same time. Moral debates around materialism, which have reverberated through the public sphere over the last decade, show how "love" acts as a tool of social reproduction while it also expresses sincere aspirations for an emotionally satisfying life. In comparative perspective, the complex of romantic love examined here reveals a recent, original synthesis of the tradition of parental arrangement and the political question of the place of love in modernity. The paper elucidates one of the contradictions within Chinese society today: the family remains central, but wider trends of individualization continue to unfold. A multifaceted understanding of love clarifies how it can bind families together while it also discourages others from pursuing romance.
\end{abstract}

Key words: romantic love, familism, individualization, marriage, morality, matchmaking, sentiments, materialism, cultural capital. 